\title{
Ultrasound student education
}

\section{Christoph F. Dietrich}

Department of Internal Medicine 2, Caritas Hospital, Bad Mergentheim, Germany

Ideally, training in ultrasound (US) should be easily accessible, standardized, systematic and transparent, allowing structured teaching and the acquisition of clinical skills. Conventional US is, generally speaking, the initial imaging modality used worldwide. It has been performed for more than three decades and has provided answers to a wide range of indications (questions) across numerous specialities. US facilitates an interdisciplinary approach and may link other subspecialists. In many countries, conventional US has long been incorporated in basic medical education and subspecialisation programs.

Technological advancements have made the US equipment accessible and affordable, with hand-held US devices that are now no bigger than a smart phone [13]. Moreover, hand-held US has the potential to support the physical examination, validating the clinical findings, may directly answer clinical questions or guide the selection of further investigations [4]. Therefore, US can be regarded as an extension of the physical examination. US devices used in this way have been variously termed echoscopes [2,3,5-8], visual stethoscopes [9], or sonoscopes [10] amongst other terms. With this simplified technique not only specific answers can be gained but also handheld US equipment may be utilised as aids to enhance medical student's education.

The advantages of US as an extended physical examination are overwhelming, particularly the instant availability of high resolution real-time imaging without the

Received Accepted

Med Ultrason

2017, Vol. 19, No 2, 131-133

Corresponding author: Prof. Dr. med. Christoph F. Dietrich

Department of Internal Medicine 2,

Caritas Krankenhaus,

Uhlandstr. 7, D-97980 Bad Mergentheim,

Germany

Phone: 49(0)7931-58-2201 / 2200

Fax: 49(0)7931-58-2290

E-mail: Christoph.dietrich@ckbm.de potential risk of exposue to ionizing radiation. Real time imaging allows guidance for interventional procedures, whilst portable small ultrasound equipment allows point of care delivery. As a non-invasive imaging method, US has high patient acceptance. The limitations of ultrasound are obvious: US is highly operator-dependent, specific procedural skills are needed, requiring hands-on training, and ultrasound does not allow examination of all body compartments since air and bone cannot be penetrated.

The introduction of ultrasound as part of the medical education has been reported since the early 80's of last century. "Anatomie am Lebenden" (which might be translated as "practical teaching of anatomy") was an early teaching experiment at the Hannover Medical School (MHH, Germany) under the guidance of R. Pabst and H. Lippert. The anatomy department implemented voluntary hands-on ultrasound courses performed by medical students on other students. Medical students participated as subjects, active tutors and teachers to enhance anatomical knowledge. These courses were well received by students. The preclinical use of ultrasound should facilitate and enhance the understanding of anatomy, physiology, pathophysiology and pathology.

It has been shown that through its diversity, US fulfils the prerequisites for medical student clinical teaching but its role differs in the various regions of the world. Today, the majority of US educational programs for the extended physical examination in medical schools are organized by clinicians rather than radiologists but historically we remember the central role of radiology. The radiological approach to teaching and training mainly relies on (passive) interpretation of US images and less on the practical skills of image acquisition [11].

For a real time method such as US, appropriate documentation is difficult to achieve. However, documentation is of importance in the quality control, feedback, learning and improvement, and medicolegal defence 
strategies $[12,13]$. Print outs or digital archiving of still images or even better, with recorded video loops should be used for recording the data.

The use of US beyond the conventional examination has been termed "point of care" US [7] which can be done by different US technologies, including high-end equipment and hand held devices. Point of care ultrasound (POCUS) has improved decision-making, patient care, and safety and therefore lessons can be learned from the disciplines of emergency medicine and critical care medicine regarding development of curricula and standards of practice. Thesedisciplines have broadened the use of US across the entire spectrum of patient care and extended this method into virtually any application where focused US examination is critical in managing a patient [7].

\section{How to teach ultrasound?}

Having shown that US is valuable in student teaching, the next question to arise is how to teach ultrasound? This can be done by classical methods such as didactic presentations by a professor lecturing in front of a large audience, or practical hands-on courses by professors or tutors (trained by the "teach-the-teacher" concept). Lectures might be appropriate for teaching the fundamental principles of US but it cannot replace the essential hands-on training to obtain US skills and experience. The "Teach-the-teacher" concept can be applied to recruit permanent and temporarily experienced students as tutors and trainers. Students' motivation to teach peers is beyond regular university structures and presents a motivating tool relevant in obtaining clinical knowledge beyond curricula. Open questions include the costs of teaching ultrasound (resources, funding), the duration of lessons, and the ratio of theoretical to practical hands-on training, starting from at least $50 \%$ of available time.

\section{What to teach?}

Anatomy, examination technique (including "knobology") as well as safety aspects of US should be included in a curriculum, and eventually the very important pathologies ("VIP"). Preclinical teaching could be implemented into the anatomy courses. At the very least, US should be included in the final year of medical education. "Teach the teacher" concepts are promising in educating student tutors and enhancing practical expertise. The value of e-learning platforms has yet to be determined. A European approach and initiative would be promising, considering regulatory bodies are local at least in federalistic systems.
The European Federation of Societies for Ultrasound in Medicine and Biology (EFSUMB) recommends that ultrasound should be used systematically as an easily accessible and instructive educational tool in the curriculum of modern medical schools. Medical students should acquire theoretical knowledge of the modality and hands-on training should be implemented, adhering to evidence-based principles $[4,14,15]$.

EFSUMB Task Force Group on student medical education in ultrasound has recently published a review of the present knowledge and experiences in a short [14] and long version [4]. Similar papers have been published in the United States $[11,12,16,17]$. More recent papers focus on specific organ systems [18].

EFSUMB has launched an Educational Portal on the EFSUMB website including a freely available textbook, the multidisciplinary EFSUMB Course Book (ECB) [19]. The online ECB is intended to complement and advance the educational purposes of EFSUMB in a modern way. It is intended to standardize and improve examination techniques, demonstrated in clear examination technique videos [20]. The ECB and teaching videos can be found in the EFSUMB course system. In addition, an atlas of echoscopy has been published for teaching point of care ultrasound [21,22]. The World Federation for Ultrasound in Medicine and Biology (WFUMB) has also developed an initiative in educating students in ultrasound.

\section{Perspective}

US in medical education is still a "work in progress". Standardization and evaluation is difficult to achieve, mainly due to multiple regulatory bodies and cultural particularities in different countries [23,24]. There is a need for standardization and modernization of teaching techniques and in the curricula used in medical teaching and practical training $[4,14]$. Future improvements will include the preclinical integration of practical US education to facilitate the understanding, and the integration of the main aspects of anatomy, physiology, pathophysiology and pathology, whilst avoiding overloading the students with excessive information. The most common and simple medical scenarios can be used to illustrate the use of ultrasound. An internet based communication platform between teachers and students should be developed [4]. US teaching is largely skill based and, therefore, requires hands-on training to achieve competency. US teaching should be also evaluated as a research tool [25] to evaluate new didactic and teaching concepts. Teaching medical students in general should also offer an academic career, including $\mathrm{PhD}$ programms. There is a growing enthusiasm for US education of medical students. 
Time has come for a structured implementation of US curricula into medical schools.

\section{References}

1. Mirabel M, Celermajer D, Beraud AS, Jouven X, Marijon E, Hagege AA. Pocket-sized focused cardiac ultrasound: strengths and limitations. Arch Cardiovasc Dis 2015;108:197-205.

2. Barreiros AP, Cui XW, Ignee A, De Molo C, Pirri C, Dietrich CF. EchoScopy in scanning abdominal diseases: initial clinical experience. Z Gastroenterol 2014;52:269-275.

3. Gilja OH, Piscaglia F, Dietrich C. EFSUMB - European Course Book: Echoscopy - A new concept in mobile ultrasound. 2014:1-21.

4. Cantisani V, Dietrich CF, Badea R, et al. EFSUMB Statement on Medical Student Education in Ultrasound [long version]. Ultrasound Int Open 2016;2:E2-7.

5. Piscaglia F, Dietrich CF, Nolsoe C, Gilja OH, Gaitini D. Birth of echoscopy. The EFSUMB point of view. Ultraschall Med 2013;34:92.

6. Dietrich CF, Cui XW, Piscaglia F. EFSUMB Case of the Month 2012 (June/July). Pocket ultrasound devices to perform EchoScopy. http://www.efsumb.org 2012.

7. Dietrich CF, Goudie A, Chiorean L, et al. Point of Care Ultrasound: A WFUMB Position Paper. Ultrasound Med Biol 2016;43:49-58.

8. Dietrich CF, Hocke M, Braden B. [Echoscopy]. Praxis (Bern 1994) 2015;104:1005-1012.

9. Gillman LM, Kirkpatrick AW. Portable bedside ultrasound: the visual stethoscope of the 21 st century. Scand J Trauma Resusc Emerg Med 2012;20:18.

10. Greenbaum LD. It is time for the sonoscope. J Ultrasound Med 2003;22:321-322.

11. Baltarowich OH, Di Salvo DN, Scoutt LM, et al. National ultrasound curriculum for medical students. Ultrasound Q 2014;30:13-19.

12. Dinh VA, Lakoff D, Hess J, et al. Medical Student Core Clinical Ultrasound Milestones: A Consensus Among Di- rectors in the United States. J Ultrasound Med 2016;35:421434.

13. Hoppmann RA, Rao VV, Poston MB, et al. An integrated ultrasound curriculum (iUSC) for medical students: 4-year experience. Crit Ultrasound J 2011;3:1-12.

14. Cantisani V, Dietrich CF, Badea R, et al. EFSUMB statement on medical student education in ultrasound [short version]. Ultraschall Med 2016;37:100-102.

15. Dietrich CF, Rudd L. The EFSUMB website, a guide for better understanding. Med Ultrason 2013;15:215-223.

16. Chiem AT, Soucy Z, Dinh VA, et al. Integration of Ultrasound in Undergraduate Medical Education at the California Medical Schools: A Discussion of Common Challenges and Strategies From the UMeCali Experience. J Ultrasound Med 2016;35:221-233.

17. Dinh VA, Fu JY, Lu S, Chiem A, Fox JC, Blaivas M. Integration of Ultrasound in Medical Education at United States Medical Schools: A National Survey of Directors' Experiences. J Ultrasound Med 2016;35:413-419.

18. Atkinson NS, Bryant RV, Dong Y, et al. WFUMB Position Paper. Learning Gastrointestinal Ultrasound: Theory and Practice. Ultrasound Med Biol 2016;42:2732-2742.

19. Dietrich CF: EFSUMB Course Book on Ultrasound (ECB). In: Dietrich CF, ed. http://www.efsumb.org 2012.

20. Tuma JB, R.; Dietrich, C.F. EFSUMB Course Book on Ultrasound, Student edition (ECBSE). http://www.efsumb.org 2015.

21. Dietrich CF. An atlas of echoscopy using a handheld device. www.efsumb.org 2015.

22. Dietrich CF. Ultraschall in der Lehre, ein kleiner Atlas der Echoskopie. Gastroenterologie Up2date 2014;10.

23. Dietrich CF, Riemer-Hommel P. Challenges for the German Health Care System. Z.Gastroenterol. 2012;50:557-572.

24. Dietrich CF. Challenges for the German Health Care System. Z.Gastroenterol. 2012;50:555-556.

25. Kratzer W, Pfeiffer M, Gebel M, Dietrich C, Adler G. [The research situation in abdominal sonography in the gastroenterology departments of university hospitals in the Federal Republic of Germany]. Z Gastroenterol 2000;38:833-834, 836. 